\title{
Resorcinolic Lipids from Yucatecan Propolis
}

\author{
Mercedes G. Herrera-López, ${ }^{a, b}$ Evelyn I. Rubio-Hernández, ${ }^{a}$ Pascal Richomme, ${ }^{c}$ \\ Andreas Schinkovitz, ${ }^{c}$ Luz M. Malvo-Irabién $^{b}$ and Luis M. Peña Rodríguez ${ }^{(*, a}$
}

\author{
${ }^{a}$ Laboratorio de Química Orgánica, Unidad de Biotecnología, \\ Centro de Investigación Científica de Yucatán, Calle 43 No. 130, Chuburná de Hidalgo, \\ CP 97205, Mérida, Yucatán, Mexico
}

${ }^{b}$ Unidad de Recursos Naturales, Centro de Investigación Científica de Yucatán, Calle 43 No. 130, Chuburná de Hidalgo, CP 97205, Mérida, Yucatán, Mexico

'SONAS EA921, SFR4207 QUASAV, University of Angers, 42 rue Georges Morel, 49070 Beaucouzé, France

\begin{abstract}
Propolis is a material produced by bees from a combination of plant exudates and wax, used to fill out cracks in the beehive and to defend against intruders and pathogenic microorganisms; it is recognized for its many biological activities and its chemical composition depends on the botanical sources close to the beehive. The objective of this investigation was to isolate and identify metabolites with antioxidant activity present in a propolis sample collected in Yucatan, Mexico. Purification of the bioactive metabolites was carried out using argentation chromatography, while the combination of ${ }^{1} \mathrm{H}$ nuclear magnetic resonance (NMR), laser desorption ionization (LDI), gas chromatography-mass spectrometry (GC-MS) and biosynthetic origin data allowed their identification as resorcinolic lipids. Finally, the resin of Mangifera indica was identified as the botanical source of these metabolites.
\end{abstract}

Keywords: argentation, antioxidants, Apis mellifera, structure elucidation, laser desorption ionization

\section{Introduction}

Propolis is a material that bees produce by collecting exudates of plants and mixing it with wax and other materials; it is used by the bees to condition their nests, to fill out cracks in the beehive and to defend the beehive against intruders and pathogenic microorganisms..$^{1-3}$ The odor, color and chemical composition of propolis depends on the botanical sources close to the beehive, as well as the geographic and climatic conditions of the region. ${ }^{4,5}$ Recently, five types of propolis have been identified according to their chemogeographic patterns: ${ }^{6}$ propolis type I, commonly found in temperate zones of West Asia, Europe and North America, where its main source is the resinous exudate of the poplar tree (Populus nigra, Salicaceae) and its main components are flavonoids without substituents in ring B and phenylpropanoid acids and their esters; propolis type II, also called Brazilian green propolis, whose main source of resin is Baccharis dracunculifolia and contains prenylated

*e-mail: 1manuel@cicy.mx phenylpropanoids and caffeoylquinic acids; propolis type III, found in Cuba and Venezuela, which contains mainly prenylated benzophenones and its main source of resin are the flowers of Clusia spp; propolis type IV, also known as Pacific type, is found in Taiwan and the Okinawa region where is derived from exudates of the fruits of Macaranga tanarius and its main components are geranil flavanones; finally, propolis type V, found in Greece, Crete and Turkey, contains mainly diterpenes and anthraquinones, and its main sources are plants of the Cupressaceae family. Propolis is also recognized for its many biological activities including antimicrobial, antitumor, antiinflammatory, antioxidant and hepatoprotective. ${ }^{7,8}$ Temperate poplar propolis (type I) and Brazilian green propolis (type II) are the two best known and most investigated types of propolis, particularly in terms of their biological activity and the polyphenolic metabolites they contain; these include artepilin $\mathrm{C}$, the phenethyl ester derivative of caffeic acid, caffeic acid, chrysin, galangin, quercetin, apigenin, kaempferol and pinocembrin. ${ }^{5,6}$ Recently, propolis has been recognized as an important source of plant bioactive 
metabolites since bees, independently of the geographical zone, are always able to find and use appropriate plant sources for propolis production; ${ }^{5,9}$ not surprisingly, a wide variety of biologically active secondary metabolites have been reported from propolis samples collected in lesser known regions of the world, including cytotoxic cycloartane triterpenoids from Myanmar propolis, ${ }^{10}$ cytotoxic galangin derivatives from Mexican propolis, ${ }^{11}$ and phenolic lipids with antioxidant activity from Asia ${ }^{1,9,12}$ and Africa. ${ }^{13}$ Here we wish to describe the isolation and identification of resorcinolic lipids with antioxidant activity from a sample of propolis collected in Yucatan, Mexico.

\section{Experimental}

\section{General}

Analytical thin layer chromatography (TLC) was carried out using aluminum-backed silica gel plates (Merck, Darmstadt, Germany, $0.2 \mathrm{~mm}$ ); chromatograms were visualized using a solution of phosphomolybdic acid $(20 \mathrm{~g})$ and ceric sulfate $(2.5 \mathrm{~g})$ in $500 \mathrm{~mL}$ of $5 \%$ sulfuric acid followed by drying and heating. Preparative TLC (prep TLC) was carried out using glass-coated $20 \times 20 \mathrm{~cm}$ silica gel plates (Merck, Darmstadt, Germany, $0.25 \mathrm{~mm}$ ) impregnated with $\mathrm{AgNO}_{3}$. Flash column chromatography purifications were carried out using silica gel (Merck, Darmstadt, Germany) 200-400 mesh, and open column chromatography (CC) purifications were carried out using $\mathrm{AgNO}_{3}$-impregnated silica gel (Sigma-Aldrich, St. Louis, USA) 70-230 mesh. Nuclear magnetic resonance (NMR) analyses were carried out in a Bruker Avance III (Billerica, USA, $400 \mathrm{MHz}$ ) or an Agilent-AR premium COMPACT (Santa Clara, USA, $600 \mathrm{MHz}$ ); samples were dissolved in $\mathrm{CDCl}_{3}$ and the residual solvent signal was used as reference.

\section{Laser desorption ionization (LDI) analysis}

General laser desorption ionization (LDI) experiments were carried out in linear negative mode on a Biflex III time of flight (TOF) mass spectrometer (Bruker, Billerica, MA, USA), equipped with a $337 \mathrm{~nm}$ pulsed nitrogen laser (model VSL-337i, Laser Sciences Inc., Boston, USA). Spectra were acquired within a mass range of $20-2000 \mathrm{~m} / \mathrm{z}$ in automatic mode. An overall of 150 acquisitions were summed for obtaining final spectra. Acceleration voltage was set to $19 \mathrm{kV}$, pulse ion extraction was $200 \mathrm{~ns}$, and laser frequency was $5 \mathrm{~Hz}$. Applied laser energy was individually adapted to sample requirements and is expressed as percent of maximal laser power as well as calculated theoretical values in $\mu \mathrm{J}$ based on the instrument's settings. Samples
$\mathrm{C} 3$ and C4 were analyzed at a laser power of $90 \%(112 \mu \mathrm{J})$ while $70 \%(105 \mu \mathrm{J})$ was used for C5.

Preparation of $\mathrm{AgNO}_{3}$-impregnated silica gel plates for prep TLC

Silica gel plates were eluted with a $5 \% \mathrm{AgNO}_{3}$ solution in acetonitrile and allowed to dry before use.

Preparation of $\mathrm{AgNO}_{3}$-impregnated silica gel for column chromatography

Silica gel (10 g) was combined with $50 \mathrm{~mL}$ of a $5 \%$ $\mathrm{AgNO}_{3}$ solution in acetonitrile and allowed to stand for 5 min before evaporating the solvent.

\section{Collection and extraction of propolis}

Propolis was collected in February 2015 by Mr Lino Mex Mex, a beekeeper of Apis mellifera in Hunucmá, Yucatán, Mexico. The propolis sample was ground to a homogeneous powder using liquid nitrogen and $1 \mathrm{~g}$ of the propolis powder was extracted three times $(2 \mathrm{~h})$ with ethanol $(20 \mathrm{~mL})$, at room temperature. The combined filtrates were kept overnight at $-18{ }^{\circ} \mathrm{C}$ and then filtered to remove waxes. ${ }^{2}$ Finally, the solvent was evaporated under reduced pressure to obtain $738 \mathrm{mg}(73.8 \%)$ of propolis extract.

\section{Collection and extraction of plant material}

The resin sample of Mangifera indica was obtained in April 2017 from a tree growing in an area close to the beehive in Hunucmá, Yucatán, Mexico. The resin $(0.9 \mathrm{~g})$ was extracted using the procedure previously described for the propolis sample to yield $13.9 \mathrm{mg}$ (1.5\%) of the corresponding resin crude extract.

Gas chromatography-mass spectrometry (GC-MS) analysis of propolis and $M$. indica extracts

The sample was analyzed in an Agilent Technologies Gas Chromatograph 6890N connected to an Agilent Technologies Mass Detector 5975B, with an ionization voltage of $70 \mathrm{eV}$; the separation was carried out using an Agilent HP-5MS column $(30 \mathrm{~m} \times 0.250 \mathrm{~mm}$ internal diameter with $0.25 \mathrm{~mm}$ film thickness), with helium as a carrier gas $\left(1 \mathrm{~mL} \min ^{-1}\right)$ and a temperature program of $110^{\circ} \mathrm{C}(2 \mathrm{~min}), 110-260{ }^{\circ} \mathrm{C}\left(15^{\circ} \mathrm{C} \mathrm{min}^{-1}\right), 260{ }^{\circ} \mathrm{C}(3 \mathrm{~min})$, 260-280 ${ }^{\circ} \mathrm{C}\left(2{ }^{\circ} \mathrm{C} \min ^{-1}\right), 280{ }^{\circ} \mathrm{C}$ (5 min), 280-300 ${ }^{\circ} \mathrm{C}$ $\left(5{ }^{\circ} \mathrm{C} \mathrm{min}{ }^{-1}\right), 300{ }^{\circ} \mathrm{C}$ (30 min). Injector and detector temperatures were set to 280 and $150{ }^{\circ} \mathrm{C}$, respectively. 
Preliminary identification of the different components was carried out by comparing their fragmentation patterns with those contained in the NIST 05 data base.

Gas chromatography-mass spectrometry (GC-MS) analysis of propolis purified fractions

The samples were analyzed in an Shimadzu Gas Chromatograph GCMS-QP2010 SE with an ionization voltage of $70 \mathrm{eV}$; the separation was carried out using a phenomenex Zebron column $(30 \mathrm{~m} \times 0.250 \mathrm{~mm}$ internal diameter with $0.25 \mathrm{~mm}$ film thickness), with helium as a carrier gas $\left(2 \mathrm{~mL} \min ^{-1}\right)$ and a temperature program of $110^{\circ} \mathrm{C}(0.5 \mathrm{~min}), 110-280^{\circ} \mathrm{C}\left(20^{\circ} \mathrm{C} \mathrm{min}^{-1}\right), 280^{\circ} \mathrm{C}(20 \mathrm{~min})$, $280-300^{\circ} \mathrm{C}\left(5^{\circ} \mathrm{C} \mathrm{min}^{-1}\right), 300^{\circ} \mathrm{C}(2 \mathrm{~min})$. Injector and detector temperatures were set to 280 and $150^{\circ} \mathrm{C}$, respectively.

\section{Determination of antioxidant activity}

The assay for the reduction of the 2,2-diphenyl1-picrylhydrazyl radical (DPPH) was carried out following a modified procedure on a previously reported methodology. ${ }^{14}$ In brief, different concentrations of each extract were prepared $\left(1 \times 10^{-1}\right.$ to $1 \times 10^{-4} \mathrm{~g}$ extract $\mathrm{mL}^{-1}$ ethanol $)$ and $200 \mu \mathrm{L}$ were added to $1800 \mu \mathrm{L}$ of DPPH $(0.1 \mathrm{mM}$ ethanol). After $30 \mathrm{~min}$ the absorbance was measured at $540 \mathrm{~nm}$. The percentage of remaining DPPH was calculated using the formula \% DPPH $=\left[(\text { AbsDPPH } 0.1 \mathrm{mM})_{\mathrm{t}=0} /\right.$ $\left.(\text { AbsDPPH sample })_{t=30}\right] \times 100$. Methanol was used as a blank and ascorbic acid (1\%) as a positive control. The assay was run three times for each extract.

\section{First purification of propolis extract (Figure S1a)}

A portion (400 mg) of the propolis extract was dissolved in dichloromethane and adsorbed in $800 \mathrm{mg}$ of silica gel. The sample was placed on top of a chromatographic column and separated by flash column chromatography $(5 \times 20 \mathrm{~cm})$ eluting with a mixture of hexane:ethylacetate:methanol 90:8:2. The collected fractions were combined into 17 (A1-A17) semipurifed fractions on the basis of their TLC chromatographic profiles. Further purification of active fraction A13 (217 mg) by flash column chromatography $(3 \times 20 \mathrm{~cm})$ eluting with hexane:ethylether 6:4 yielded 11 (B1-B11) new semipurified fractions. Finally, prep TLC purification of active fraction B5 $(9 \mathrm{mg})$ using a multiple elution (four times) with dichloromethane:methanol 19:1 on $\mathrm{AgNO}_{3}$-impregnated silica gel plates produced eight fractions (C1-C8) of which fractions $\mathrm{C} 3(1.2 \mathrm{mg})$, $\mathrm{C} 4(1.0 \mathrm{mg})$ and $\mathrm{C} 5(1.3 \mathrm{mg})$ were active in the DPPH radical reduction assay.
Second purification of propolis extract (Figure S1b)

A portion $(420 \mathrm{mg}$ ) of the crude propolis extract was dissolved in dichloromethane and adsorbed in $800 \mathrm{mg}$ of silica gel (200-400 mesh). The sample was placed on top of a chromatographic column $(5 \times 20 \mathrm{~cm})$ and separated by flash CC using a mixture of hexane-ethyl ether $6: 4+1 \mu \mathrm{L} \mathrm{mL}^{-1}$ of formic acid. The collected fractions were combined into eleven (D1 to D11) semipurifed fractions. Open CC $(1.5 \times 30 \mathrm{~cm})$ purification of fraction D5 $(67.7 \mathrm{mg})$ using $\mathrm{AgNO}_{3}$-impregnated silica gel and a mixture of dichloromethane-methanol 19:1 as eluent yielded semipurified fractions E2 $(4.2 \mathrm{mg})$, E3 $(19 \mathrm{mg})$ and E4 $(6.2 \mathrm{mg})$ that were combined and purified by multiple-elution (four times) prep TLC using a mixture of dichloromethane-methanol 19:1 on $\mathrm{AgNO}_{3}$-impregnated silica gel plates to produce fraction F3 $(1.8 \mathrm{mg})$. Similarly, open CC $(1.5 \times 30 \mathrm{~cm})$ purification of fractions D6 $(14.8 \mathrm{mg})$ and D7 (67.7 $\mathrm{mg})$ combined yielded semipurified fractions G3 $(8.7 \mathrm{mg})$ and $\mathrm{G} 4(10.3 \mathrm{mg})$ that were combined and purified by multiple-elution (four times) prep TLC using a mixture of dichloromethane-methanol 19:1 on $\mathrm{AgNO}_{3}$-impregnated silica gel plates to produce fraction $\mathrm{H} 3(1.8 \mathrm{mg})$. Finally, open $\mathrm{CC}(1.5 \times 30 \mathrm{~cm})$ purification of fraction D8 $(91.2 \mathrm{mg})$ yielded the semipurified fractions I5 $(11 \mathrm{mg})$ and $\mathrm{I} 6(9.9 \mathrm{mg})$ that were combined and purified by multiple-elution (four times) prep TLC using a mixture of dichloromethane-methanol 19:1 on $\mathrm{AgNO}_{3}$-impregnated silica gel plates to produce fraction J2 $(1.8 \mathrm{mg})$. Prep TLC purification of fractions I9 $(6.1 \mathrm{mg})$, I10 $(11.9 \mathrm{mg})$ and I1 $(4.4 \mathrm{mg}$ ) combined using a multiple-elution (four times) with a mixture of dichloromethane-methanol 19:1 on $\mathrm{AgNO}_{3}$-impregnated silica gel plates yielded fractions $\mathrm{K} 3$ (3.1 mg) and K4 (2.8 mg).

\section{Results and Discussion}

The bioassay-guided purification of the propolis extract, with a strong (half maximal inhibitory concentration $\left(\mathrm{IC}_{50}\right)$ $0.71 \mathrm{mg} \mathrm{mL}^{-1}$ ) antioxidant activity when tested in the DPPH reduction assay, produced fraction B5 showing a single component with antoxidant activity in its TLC profile (Figure S2a, Supplementary Information (SI) section). However, the GC-MS analysis of fraction B5 indicated the presence of four major components (Figure S2b, SI section), all of them with a base peak at $\mathrm{m} / \mathrm{z} 124$ and a fragmentation pattern (Figure 1a) coinciding with that of resorcinolic lipid structures in the database. The fact that the fragment ion of the base peak, which can be explained by a methyl-substituted 1,3-benzenediol structure (Figure 1b), was common to all the components in fraction B5 suggested 
(a)

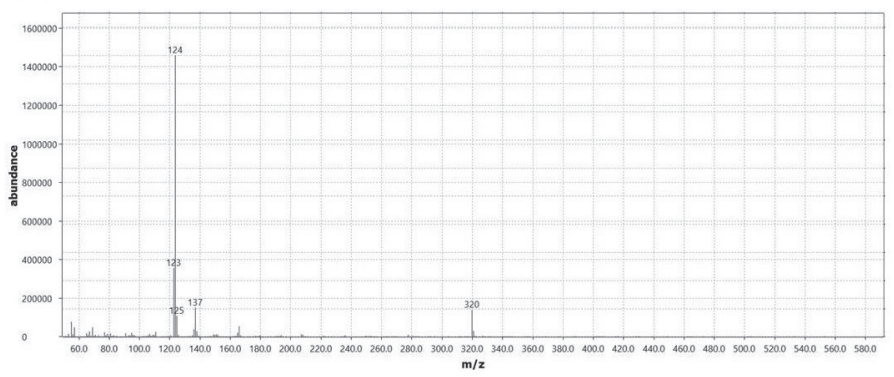

(b)<smiles>CC1=CC(O)=CC(O)C1</smiles>

Figure 1. (a) Fragmentation pattern of one of the components $\left(t_{\mathrm{R}} 17.8 \mathrm{~min}\right.$ ) in fraction B5 showing a molecular ion at $\mathrm{m} / \mathrm{z}, 320$ and a base peak at $\mathrm{m} / \mathrm{z}, 124$; (b) structure corresponding to the base peak fragment at $\mathrm{m} / z .124\left(\mathrm{C}_{7} \mathrm{H}_{8} \mathrm{O}_{2}\right)$.

that they all shared the same resorcinolic basic structure but differed in the length of the lipidic hydrocarbon chain.

Phenolic lipids have often been reported as inseparable mixtures from species of the Anacardiaceae family and from propolis samples collected in different parts of the world: $;^{1,9,12,13,15}$ accordingly, various attempts to purify the components in fraction B5 using ordinary chromatographic methods proved to be unsuccessful. However, argentation chromatography, i.e., the impregnation of silica gel and other adsorbents with silver nitrate, has been commonly used to separate structurally-similar metabolites such as triglycerides and lipids, terpenes, essential oils components and resin constituents which differ in the number or geometry of their double bonds, ${ }^{16,17}$ and previous reports have described the use of argentation chromatography as an alternative to separate homologues of phenolic lipids with varying degrees of side-chain unsaturation. ${ }^{18}$ In this investigation, argentation of silica gel plates greatly improved the separation of the bioactive components in fraction B5 (Figure S3, SI section); prep TLC purification of fraction B5 using silica gel plates impregnated with silver nitrate produced the purified bioactive fractions $\mathrm{C} 3-\mathrm{C} 5$ (Figure S4, SI section).

While fractions $\mathrm{C} 3$ and $\mathrm{C} 5$ each showed a single bioactive metabolite on TLC, fraction C4 appeared to be a mixture of the metabolites in fractions $\mathrm{C} 3$ and $\mathrm{C} 5$. The ${ }^{1} \mathrm{H}$ NMR of C3 (Figure S5, Table S1, SI section) showed the expected signals for a resorcinolic lipid structure, ${ }^{19-21}$ namely two signals corresponding to three aromatic protons at $6.24(2 \mathrm{H})$ and $6.17(1 \mathrm{H}) \mathrm{ppm}$, one two-proton signal at $4.64 \mathrm{ppm}$, corresponding to the protons of the two phenolic hydroxyl groups, a two-proton triplet at $2.48 \mathrm{ppm}$, corresponding to the protons of the benzylic methylene, and a three proton triplet at $0.87 \mathrm{ppm}$, corresponding to the terminal methyl group of the hydrocarbon chain. However, both the LDI and GC-MS analyses of C3 showed the presence of two components with parent ion peaks at $m / z, 319 / 347$ and 320/348, respectively (Figure S6, SI section), corresponding to the molecular formulae
$\mathrm{C}_{21} \mathrm{H}_{36} \mathrm{O}_{2} / \mathrm{C}_{23} \mathrm{H}_{40} \mathrm{O}_{2}$. To identify the two components in $\mathrm{C} 3$ it was necessary to consider the biosynthetic origin of resorcinolic lipids, ${ }^{22-24}$ taking into account that the hydrocarbon chain of resorcinolic lipids originates from a fatty acyl-coenzyme A (CoA) starter unit (Figure S7, SI section), and the fact that there are only one C-16 (palmitic) and one C-18 (stearic) fully saturated fatty acids, the bioactive resorcinolic lipids in $\mathrm{C} 3$ were identified as 1,3-benzenediol-5-pentadecyl (1) and 1,3-benzenediol5-heptadecyl (2) (Figure 2). Both bioactive metabolites have previously been reported to co-occur in Merulius incarnatus ${ }^{25}$ and triticale bran, ${ }^{26}$ and in propolis samples from Cameroon ${ }^{13}$ and Indonesia. ${ }^{1}$ Additionally, 2 has been reported from the latex of Mangifera indica. ${ }^{27}$

The ${ }^{1} \mathrm{H}$ NMR of $\mathrm{C} 5$ (Figure S8, Table S1, SI section) showed the same signals observed in the spectrum of C3 plus one two-proton signal at 5.35 and a four-proton signal at $2.02 \mathrm{ppm}$ corresponding to vinylic and allylic protons, respectively; these signals suggested the presence of a double bond in the lipid part of the molecule. This was confirmed by the LDI and GC-MS analyses of C5 which showed two components with parent ion peaks at $\mathrm{m} / \mathrm{z} 345 / 373$ and $346 / 374$ (Figure S9, SI section), corresponding to molecular formulae $\mathrm{C}_{23} \mathrm{H}_{38} \mathrm{O}_{2} / \mathrm{C}_{25} \mathrm{H}_{42} \mathrm{O}_{2}$ and confirming the presence of an extra unsaturation in the resorcinolic lipid structure. The location of the double bond in the lipidic chain of resorcinolic lipids is often established by analyzing the fragmentation pattern of the corresponding dimethyl disulfide-trimethylsilyl derivatives after GC-MS analyses..$^{13,16}$ In this case, the bioactive resorcinolic lipids in $\mathrm{C} 5$ were identified by combining the information from their biosynthetic origin and their MS fragmentation pattern after GC-MS analysis. Even though there are five $\mathrm{C} 18$-carbon fatty acids with one unsaturation $(\Delta 3,6,9,11$ or 13$)$ that can be used as a starting unit to produce a resorcinolic lipid with a molecular weight of 346 , and there are four C20-carbon fatty acids with one unsaturation $(\Delta 9,11,13$ or 15$)$ that can be used as a starting unit to produce a resorcinolic lipid with a molecular weight 


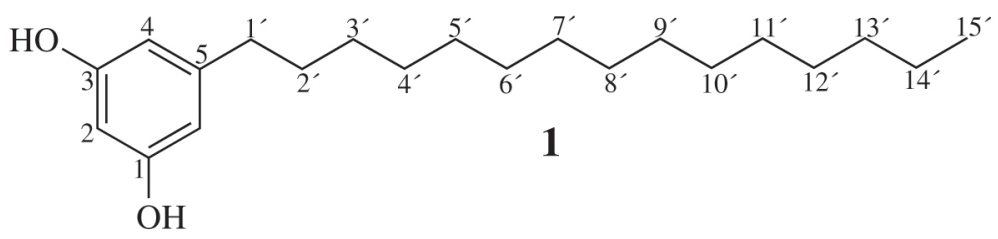

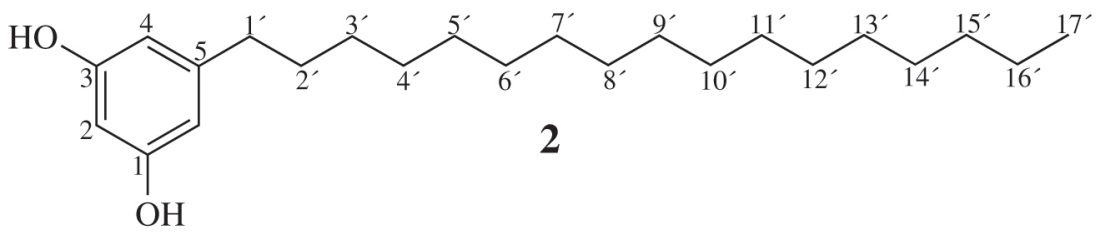

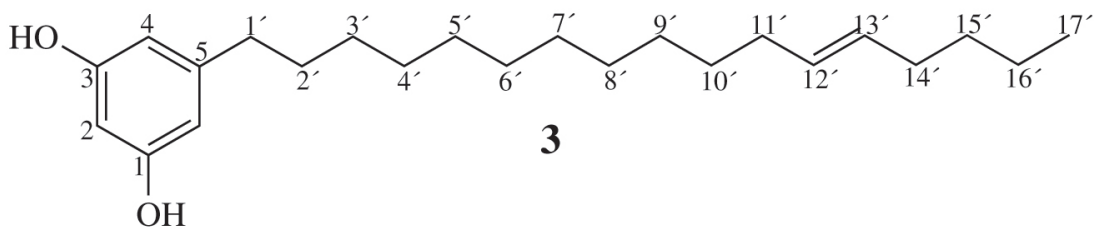

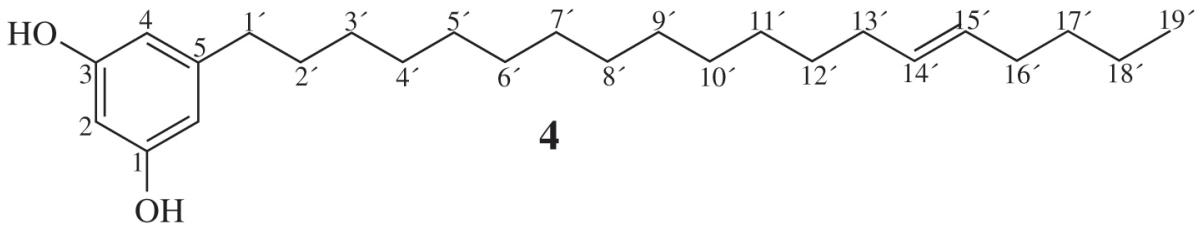

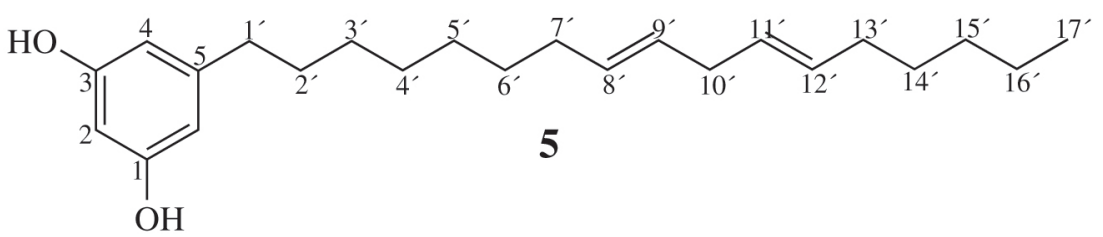

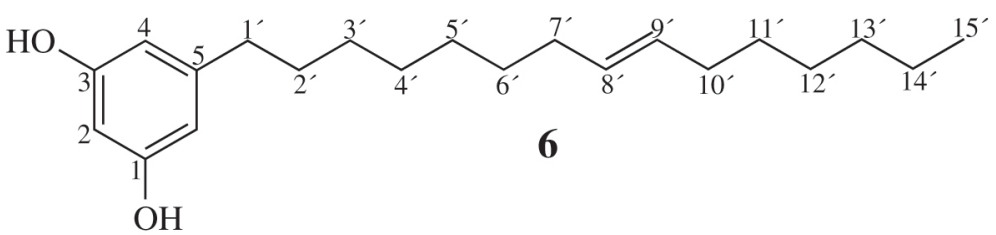

Figure 2. Structures of resorcinolic lipids identified in the propolis sample collected in Yucatan, Mexico.

of 374, the fragmentation pattern of both components in the GC-MS analysis of C5 showed a fragment ion at $\mathrm{m} / z$ 97, together with fragments and parent ion peaks at $\mathrm{m} / \mathrm{z}, 249 / 346$ and $\mathrm{m} / \mathrm{z} 277 / 374$ in the fragmentation pattern of each component (Figures S10 and S11, SI section); since the $m / z, 249 / 97$ and $m / z, 277 / 97$ fragments can only result from an allylic cleavage in an 5-omega C18 and C20 fatty acid-derived resorcinolic lipids, respectively, the bioactive components in $\mathrm{C} 5$, one with a $\Delta 1318$-carbon and the other with a $\Delta 1520$-carbon fatty acyl-CoA starter units, were identified as 1,3-benzenediol-5-(12-heptadecenyl) (3) and 1,3-benzenediol-5-(14-nonadecenyl) (4), respectively, (Figure 2). Metabolite 3 has been reported from the peel of the mango (M. indica) fruit, ${ }^{28}$ while $\mathbf{4}$ has been isolated from the roots of Ardisia silvestris ${ }^{29}$ as well as from wheat bran oil ${ }^{30}$ additionally, both metabolites have been reported from triticale bran ${ }^{26}$ and a propolis sample from Cameroon. ${ }^{13}$ Finally, and even though $\mathrm{C} 4$ appeared to be a mixture of the metabolites in $\mathrm{C} 3$ and C5, its LDI and GC-MS analyses (Figure S12, SI section) showed only two components with parent ion peaks at $m / z 319 / 373$ and $320 / 374$, respectively, indicating that the purified fraction $\mathrm{C} 4$ was in fact a mixture of the bioactive resorcinolic lipids $\mathbf{1}$ and $\mathbf{4}$.

In an attempt to obtain the resorcinolic lipids 1-4 in pure form and/or isolate other resorcinolic lipids, the propolis extract was purified using argentation chromatography throughout the purification process; this resulted in the isolation of bioactive fractions $\mathrm{H} 3, \mathrm{~K} 3$ and $\mathrm{K} 4$, none of which showed a similar composition to that of fraction B5. However, the GC-MS analysis of $\mathrm{H} 3$ showed three major components corresponding to the bioactive resorcinolic lipids 1, 2 and 4. A similar analysis of K4 showed the 
presence of a single component (Figure S13, SI section) with a parent ion peak at $\mathrm{m} / \mathrm{z} 344$, corresponding to a molecular formula of $\mathrm{C}_{23} \mathrm{H}_{36} \mathrm{O}_{2}$; the number of unsaturation sites calculated from the formula suggested a resorcinolic lipid structure with two double bonds in the hydrocarbon chain. This was confirmed by a four vinylic proton-multiplet at $5.35 \mathrm{ppm}$ in the ${ }^{1} \mathrm{H}$ NMR spectrum of K4 (Figure S14, SI section), together with two signals at $2.77(2 \mathrm{H})$ and $2.05(4 \mathrm{H}) \mathrm{ppm}$ corresponding to the six protons of three allylic methylenes (Figure S14 and Table S1, SI section). Since linoleic acid is the only 18-carbon fatty acid with two double bonds ( $\Delta 9$ and $\Delta 12)$ that can act as a starter unit, the bioactive resorcinolic lipid in $\mathrm{K} 4$ was identified as 1,3-benzenediol-5-(8,11-heptadecadienyl) (5) (Figure 2). Metabolite $\mathbf{5}$ has also been reported from M. incarnatus ${ }^{25}$ and the peel of mango (M. indica) fruits, ${ }^{31}$ as well as from propolis samples in Indonesia ${ }^{1}$ and Brazil. ${ }^{15}$ Finally, the GC-MS analysis of K3 showed the presence of four components (Figure S15, SI section), three of them identified as the bioactive resorcinolic lipids $\mathbf{3}, \mathbf{4}$, and 5. The unknown component showed a parent ion peak at $m / z 318$, corresponding to a molecular formula of $\mathrm{C}_{21} \mathrm{H}_{34} \mathrm{O}_{2}$ which suggested a resorcinolic lipid having a mono-unsaturated 16-carbon fatty acyl-CoA as the starter unit. Since palmitoleic acid is the only known 16-carbon mono-unsaturated fatty acid, the unknown bioactive component in $\mathrm{K} 3$ was identified as 1,3-benzenediol5-(8-pentadecenyl) (6) (Figure 2), a metabolite previously reported from $M$. incarnatus. ${ }^{25}$

Since resorcinolic lipids have been reported to be present in the fruits and resin of Mangifera indica, ${ }^{13,32}$ we compared the GC-chromatographic profile of the resin of a mango tree (M. indica) growing close to the beehive, with the chromatographic profile of the active fractions, and were able to detect the presence of resorcinolic lipids $\mathbf{1}, \mathbf{3}, \mathbf{5}$ and $\mathbf{6}$ in the resin of the tree (Figure 3). This result confirms the resin of $M$. indica as one of the botanical sources of this type of metabolites in the propolis sample collected in Yucatan.

(a)

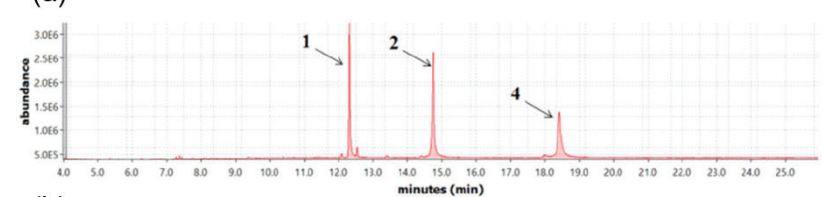

(b)

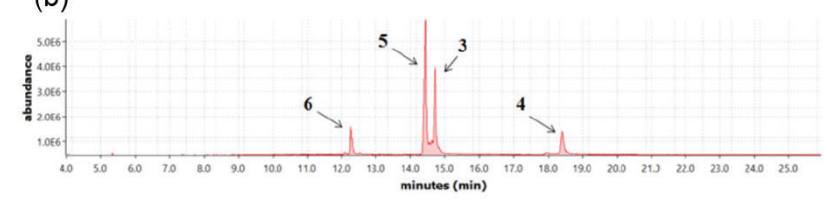

A recent study of a sample of the propolis extract used in this investigation resulted in the identification of cycloartanes and pentacyclic triterpenes ${ }^{33}$ however, the botanical origin of most of these triterpenoids could not be traced back to the resin of $M$. indica but to the resin of Bursera simaruba, a common resinferous tree found in Yucatan, or to plants belonging to the Anacardiaceae or Clusiaceae families. These results, together with those presented here, confirm the fact that bees use more than one botanical source in their production of propolis and that Yucatecan propolis has a composition which appears to be different from that reported for propolis samples collected in other parts of the world.

\section{Conclusions}

The results of this investigation confirm the importance of argentation for the separation of structurally-related resorcinolic lipids and the relevance of LDI, GC-MS and biosynthetic origin data to unequivocally identify structurally-related resorcinolic lipids. Finally, the results obtained allowed the identification of metabolites 1-6 as those responsible for the antioxidant activity originally detected in the propolis crude extract.

\section{Supplementary Information}

Supplementary information (chromatographic procedures used for the purification of the propolis extract, TLC chromatographic profile, ${ }^{1} \mathrm{H}$ NMR data, LDI spectrums, GC-MS chromatographic profiles and fragmentation patterns of fractions obtained and the biosynthetic pathway of resorcinol lipids are included) is available free of charge at http://jbcs.sbq.org.br as PDF file.

\section{Acknowledgments}

The authors wish to thank Dimitri Beard for NMR spectra and GC-MS analysis, and Gabriel Dzib technical

(c)

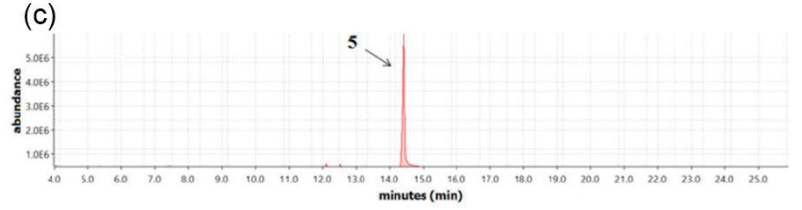

(d)

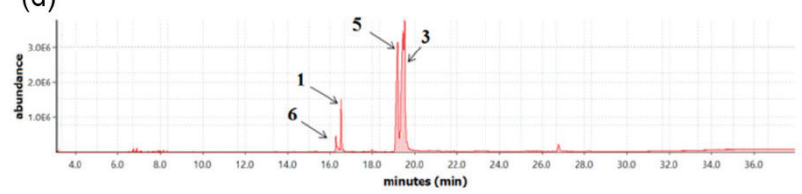

Figure 3. GC-MS chromatographic profiles of purified fractions H3 (a), K3 (b) and K4 (c), and of M. indica resin (d). 
support in the field; M. G. H. L. wishes to thank CONACYT for scholarship No. 262149. Financial support from CICY's "Programa de Fortalecimiento a la Investigación Multidisciplinaria 2015" and SEP-CONACYT-ANUIESECOS-NORD (Mexico-France) collaborative Project No. 276520 is also gratefully acknowledged.

\section{References}

1. Trusheva, B.; Popova, M.; Koendhori, E. B.; Tsvetkova, I.; Naydenski, C.; Bankova, V.; Nat. Prod. Res. 2011, 25, 606.

2. Boisard, S.; Huynh, T. H. T.; Escalante-Erosa, F.; HernándezChavez, L. I.; Peña-Rodríguez, L. M.; Richomme, P.; J. Apic. Res. 2016, 54, 350.

3. Simone-Finstrom, M.; Spivak, M.; Apidologie 2010, 41, 295.

4. Schmidt, E. M.; Stock, D.; Chada, F. J. G.; Finger, D.; Sawaya, A.; Eberlin, M. N.; Felsner, M. L.; Quinaia, S. P.; Monteiro, M. C.; Torres, Y. R.; BioMed Res. Int. 2014, 2014, 257617.

5. Huang, S. A.; Zhang, C. P.; Wang, K.; Li, G. Q.; Hu, F. L.; Molecules 2014, 19, 19610.

6. Salatino, A.; Fernandes-Silva, C. C.; Righi, A. A.; Salatino, M. L. F.; Nat. Prod. Rep. 2011, 28, 925.

7. Bankova, V.; Popova, M.; Trusheva, B.; Chem. Cent. J. 2014, 8, DOI: $10.1186 / 1752-153 X-8-28$.

8. Toreti, V. C.; Sato, H. H.; Pastore, G. M.; Park, Y. K.; J. Evidence-Based Complementary Altern. Med. 2013, 2013, 697390.

9. Popova, M.; Dimitrova, R.; Al-Lawati, H. T.; Tsvetkova, I.; Najdenski, H.; Bankova, V.; Chem. Cent. J. 2013, 7, 158.

10. Li, F.; Awale, S.; Zhang, H. Y.; Tezuka, Y.; Esumi, H.; Kadota, S.; J. Nat. Prod. 2009, 72, 1283.

11. Li, F.; Awale, S.; Tezuka, Y.; Esumi, H.; Kadota, S.; J. Nat. Prod. 2010, 73, 623.

12. Teerasripreecha, D.; Phuwapraisirisan, P.; Puthong, S.; Kimura, K.; Okuyama, M.; Mori, H.; Kimura, A.; Chanchao, C.; BMC Complementary Altern. Med. 2012, 12, DOI: 10.1186/14726882-12-27.

13. Kardar, M. N.; Zhang, T.; Coxon, G. D.; Watson, D. G.; Fearnley, J.; Seidel, V.; Phytochemistry 2014, 106, 156.

14. Brand-Williams, W.; Cuvelier, M. E.; Berset, C.; LWT-Food Sci. Technol.1995, 28, 25.
15. Silva, M. S. S.; de Lima, S. G.; Oliveira, E. H.; Lopes, J. A. D.; Chaves, M. H.; Reis, F. A. M.; Citó, A. M. G. L.; Ecletica Quim. 2008, 33, 53 .

16. Lawrence, B. M.; J. Chromatogr. A 1968, 38, 535.

17. de Vries, B.; J. Am. Oil Chem. Soc. 1964, 41, 403.

18. Kozubek, A.; Tyman, J. H. P.; Chem. Rev. 1999, 99, 1.

19. Jalil, J.; Jantan, I.; Shaari, K.; Abdul Rafi, I. A.; Pharm. Biol. 2004, 42, 457.

20. Zheng, Y.; Wu, F. E.; J. Asian Nat. Prod. Res. 2007, 9, 545.

21. Anh, N. H.; Ripperger, H.; Schmidt, J.; Porzel, A.; Van Sung, T.; Adam, G.; Planta Med. 1996, 62, 479.

22. Funa, N.; Ozawa, H.; Hirata, A.; Horinouchi, S.; Proc. Natl. Acad. Sci. U. S. A. 2006, 103, 6356.

23. Schultz, D. J.; Wickramasinghe, N. S.; Klinge, C. M. In Integrative Plant Biochemistry - Recent Advances in Phytochemistry, vol. 40, $1^{\text {st }}$ ed.; Romeo, J. T., ed.; Elsevier: Amsterdam, The Netherlands, 2006.

24. Dewick, P. M.; Medicinal Natural Products, vol. 1, $3^{\text {rd }}$ ed.; John Wiley \& Sons Ltd.: Chichester, United Kingdom, 2009.

25. Jin, W.; Zjawiony, J., K.; J. Nat. Prod. 2006, 69, 704.

26. Agil, R.; Oomah, D. B.; Mazza, G.; Hosseinian, F. S.; Food Bioprocess Technol. 2011, 5, 2655.

27. Bandyopadhyay, C.; Gholap, A. S.; Mamdapur, V. R.; J. Agric. Food Chem. 1985, 33, 377.

28. Cojocaru, M.; Droby, S.; Glotter, E.; Goldman, A.; Gottlier, H. E.; Jacoby, B.; Prusky, D.; Phytochemistry 1986, 25, 1093.

29. Hoang Anh, N.; Ripperger, H.; Schmidt, J.; Porzel, A.; Van Sung, T.; Adam, G.; Planta Med. 1996, 62, 480.

30. Iwatsuki, K.; Akihisa, T.; Tokuda, H.; Ukiya, M.; Higashihara, H.; Mukainaka, T.; Iizuka, M.; Hayashi, Y.; Kimura, Y.; Nishino, H.; J. Agric. Food Chem. 2003, 51, 6683.

31. Knodler, M.; Conrad, J.; Wenzig, E. M.; Bauer, R.; Lacorn, M.; Beifuss, U.; Carle, R.; Schieber, A.; Phytochemistry 2008, 69, 988.

32. Aguilar-Ortigoza, C. J.; Sosa, V.; Aguilar-Ortigoza, M.; Econ. Bot. 2003, 57, 354.

33. Herrera-López, M. G.; Rubio-Hernández, E. I.; Leyte-Lugo, M. A.; Schinkovitz, A.; Richomme, P.; Calvo-Irabién, L. M.; Peña-Rodríguez, L. M.; Phytochem. Lett. 2019, 29, 25.

Submitted: March 20, 2019 Published online: July 11, 2019 